\title{
Studies on single polymer composites of poly(methyl methacrylate) reinforced with electrospun nanofibers with a focus on their dynamic mechanical properties
}

\author{
K. P. Matabola ${ }^{1,3}$, A. R. de Vries ${ }^{2 *}$, A. S. Luyt ${ }^{3}$, R. Kumar ${ }^{1}$ \\ ${ }^{1}$ CSIR Materials Science and manufacturing, P. O. Box 1124, Port Elizabeth 6000, South Africa \\ ${ }^{2}$ Department of Science and Technology, Private Bag X 894, Pretoria 0001, South Africa \\ ${ }^{3}$ Department of Chemistry, University of the Free State (Qwaqwa Campus), Private Bag X 13, Phuthaditjhaba 9866, \\ South Africa
}

Received 22 November 2010; accepted in revised form 18 January 2011

\begin{abstract}
The dynamic mechanical properties of single polymer composites of poly(methyl methacrylate) (PMMA) reinforced with electrospun PMMA nanofibers of different diameters are reported. The effect of electrospinning parameters on the morphology and diameters of the electrospun high molecular weight PMMA was investigated in order to obtain suitable diameters for the reinforcing fibers. Scanning electron microscopy (SEM) was used to study the morphology and diameters of the nanofibers produced at different electrospinning conditions. It was found that polymer solution concentration influences the diameter of the electrospun nanofibers more than the spinning voltage and spinning distance. SEM analysis of the PMMA nanofibers showed that the fibers had a smooth, regular and cylindrical morphology with no beads and junctions. Effects of the processing temperature for the preparation of the single polymer composites via film stacking were investigated. Dynamic mechanical analysis showed a pronounced improvement in the storage modulus of the composites compared to the matrix.
\end{abstract}

Keywords: nanomaterials, electrospinning, poly(methyl methacrylate), single polymer composites

\section{Introduction}

Single polymer composites refer to composites in which both reinforcements and matrix are from the same polymer, thereby supporting the ease of recyclability [1]. The concept was first described by Capiati and Porter [2] decades ago for high density polyethylene. Following their pioneering work, single polymer composites have been successfully manufactured for a variety of different semi-crystalline and amorphous polymers, including polyethylene [3], polypropylene [4], poly(ethylene napthalate) [5], poly(lactic acid) [6], polyamide [7] and poly(methyl methacrylate) (PMMA) [8-9]. Several techniques have been reported for the production of these composites, such as film-stacking [10] which will be used in this study, hot compaction [11] and co-extrusion [12]. The underlying basis of the techniques is to set a suitable processing window that utilises the difference in the melting temperature of the reinforcement and the matrix [13]. The small difference in melting temperature between the fiber and the matrix poses a challenge during fabrication. To overcome this problem, polymers with the same chemical composition but different chemical structure than the fiber were mostly used [14]. PMMA single polymer composites with improved mechanical properties [8-9] were produced by hot compaction utilising the melt spun micron-size fibers.

\footnotetext{
${ }^{*}$ Corresponding author, e-mail: andrew.devries@dst.gov.za
} (c) BME-PT 
Unlike the single polymer composites involving semi-crystalline polymers, PMMA single polymer composites are unique in the sense that they were fabricated from amorphous PMMA with sufficient amount of molecular orientation [8]. Our hypothesis is that the composite performance can further be improved by using PMMA nanofibers and these fibers can be produced by the electrospinning technique.

Electrospinning is one of the recently recognised fields of nanoscience and nanotechnology that has the potential to produce polymer nanofibers [1518]. Although many reports are already available on PMMA electrospun nanofibers, PMMA of much lower molecular weight was used in these studies $[19,20]$. It is assumed that PMMA of higher molecular weight would serve as better reinforcement in single PMMA composites than those of lower molecular weight.

In this work, PMMA nanofibers of different diameters were produced by electrospinning technique and are used as reinforcements in PMMA single polymer composites. Effects of electrospinning parameters on the morphology and diameter of the nanofibers were investigated by scanning electron microscopy (SEM). The composites were manufactured by the film stacking technique applying a two-component approach and the properties of the composites were assessed by dynamic mechanical analyser (DMA).

\section{Experimental}

\subsection{Materials}

High molecular weight PMMA (PMMA ${ }_{\text {high }}, M_{\mathrm{w}}=$ $996000 \mathrm{~g} / \mathrm{mol}$ ) was purchased from Sigma Aldrich (Schenelldorf, Germany). N,N-dimethylformamide (DMF) and tetrahydrofuran (THF) were obtained from Sigma Aldrich (Schenelldorf, Germany) and Labscan Analytical Sciences (Gliwice, Poland), respectively, and used without any further purification. Polymer solutions for the electrospinning of $\mathrm{PMMA}_{\text {high }}$ were prepared by dissolving 4, 5 and $6 \mathrm{wt} \%$ PMMA in a 1:1 THF:DMF solvent mixture. The electrospun $\mathrm{PMMA}_{\text {high }}$ nanofibers were used as the reinforcing phase and a low molecular weight PMMA (PMMA low $_{1} 90000 \mathrm{~g} / \mathrm{mol}$, Altuglass V825TL grade) purchased from Advanced Polymers (Altuglass International, Rho (MI), Italy) was used as the matrix material.

\subsection{Electrospinning process}

In the electrospinning process, $\mathrm{PMMA}_{\text {high }}$ solutions were placed in a $5 \mathrm{ml}$ syringe and gravity-fed through the tip. A copper wire was inserted into the polymer solution to act as a positive electrode. A high voltage supply, manufactured at University of Stellenbosch, Cape Town, South Africa, was used to charge the polymer solution, which resulted in an accelerated fluid jet towards a grounded aluminium collector. The electrospinning voltages used were 10 , 15,20 and $25 \mathrm{kV}$ at a spinning distance of 10 and $15 \mathrm{~cm}$. The electrospinning process was done in a horizontal mode in a fume hood at room temperature.

\subsection{Composite preparation}

The $P M M A_{\text {low }}$ pellets were dried in an oven at $60^{\circ} \mathrm{C}$ for $12 \mathrm{~h}$ before use. They were compression moulded to a film (layer thickness of $0.80 \mathrm{~mm}$ ) on a CSIR (Port Elizabeth, South Africa) in-house compression moulding machine at a temperature of $200^{\circ} \mathrm{C}$ and a pressure of $2.5 \mathrm{bar}$. Two layers of nanofiber mats were sandwiched in-between four layers of a PMMA film sandwich structure. The sandwich material was then placed between two plates separated by two teflon sheets and compression moulded for $10 \mathrm{~min}$ at a low pressure ( $0.5 \mathrm{bar}$ ) and for $5 \mathrm{~min}$ at a higher pressure $(2.5 \mathrm{bar})$. The processing temperatures used were 140,150 and $160^{\circ} \mathrm{C}$, respectively at constant pressure and holding time. After compression moulding, the samples were watercooled under pressure for $7 \mathrm{~min}$.

\subsection{Characterization}

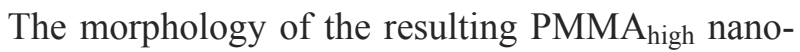
fibers was characterised by SEM. A Gemini LEO 1525 FE-SEM (Carl Zeiss NTS GmbH, Germany) at an accelerating voltage of 5 or $10 \mathrm{kV}$ using an Inlens detector was used. Before the observation, the fibers were coated with a $20 \mathrm{~nm}$ layer of evaporated carbon using an Emitech K950X evaporator (Quorum Technologies, Kent, UK). SEM analysis was also used to determine the intactness of the nanofibers on the cross-sectional area of the PMMA single polymer composites. The samples were prepared by fracturing under 3-point bending. Differential scanning calorimetry (DSC) was carried out with a Perkin Elmer DSC 7 (Life and Analytical Science, Shelton, USA) under nitrogen atmosphere. About 
$5 \mathrm{mg}$ of sample was hermetically sealed in an aluminium pan for the measurements. The DSC samples were heated from 25 to $330^{\circ} \mathrm{C}$ at a heating rate of $10^{\circ} \mathrm{C} / \mathrm{min}$. The dynamic mechanical properties of the composite samples were determined using a Perkin Elmer DMA 8000 (Life and Analytical Science, Shelton, USA) in a dual cantilever bending mode at a frequency of $1 \mathrm{~Hz}$ and a scan rate of $2^{\circ} \mathrm{C} / \mathrm{min}$. The temperature was varied from room temperature to $160^{\circ} \mathrm{C}$. The sample dimensions were $50 \mathrm{~mm} \times 9 \mathrm{~mm} \times 4 \mathrm{~mm}$.

\section{Results and discussion}

\subsection{Electrospinning of PMMA nanofibers}

The influence of polymer solution concentration, applied voltage and spinning distance on the morphology and diameters of the electrospun $\mathrm{PMMA}_{\text {high }}$ nanofibers were investigated in order to obtain nanofibers of different diameters. This is important for studying the effect of the fiber diameter on the properties of the single polymer composites of PMMA. Effects of various parameters on the morphology and diameter of the electrospun fibers are discussed.

\section{Effect of PMMA concentration}

The polymer solution concentration determines the spinnability of a solution [21]. The concentrations examined in this study were 4,5 and $6 \mathrm{wt} \%$ $\mathrm{PMMA}_{\text {high }}$ in a DMF/THF solvent mixture. The average fiber diameters were determined from measuring the diameters of 40 individual fibers. It can be seen from Table 1 that the fiber diameter increases with an increase in polymer solution concentration. The smaller diameter of the nanofibers from the lower concentrations is the result of the solution being stretched easily during electrospinning. The larger nanofiber diameters at high concentrations are attributed to the viscosity of the solution that was high enough to lower the bending instability of the jet. The solution becomes resistant to stretching by the electrical charges on the electrospinning jet [22].

Figure 1 shows the electron micrographs of the nonwoven fiber mats electrospun from 4, 5 and $6 \mathrm{wt} \%$ $\mathrm{PMMA}_{\text {high }}$ solutions at a voltage of $15 \mathrm{kV}$ onto an electrically grounded electrode positioned $10 \mathrm{~cm}$ from the syringe tip. The SEM images show the presence of fibers in the 200 to $900 \mathrm{~nm}$ range with smooth, regular and cylindrical morphology. No beads and junctions were observed in the fibers.

\section{Effect of applied voltage}

Table 1 shows the correlation between the fiber diameter and the applied voltage of the PMMA fibers electrospun at a spinning distance of 10 and $15 \mathrm{~cm}$.

Table 1. Effect of different electrospinning parameters on the diameters of PMMA fibers obtained from PMMA high polymer solution

\begin{tabular}{|c|c|c|c|c|c|c|}
\hline \multirow{3}{*}{$\begin{array}{c}\text { Applied voltage } \\
{[\mathrm{kV}]}\end{array}$} & \multicolumn{2}{|c|}{$4 \mathrm{wt} \%$} & \multicolumn{2}{|c|}{$5 \mathrm{wt} \%$} & \multicolumn{2}{|c|}{$6 \mathrm{wt} \%$} \\
\hline & \multicolumn{6}{|c|}{ Average diameter [nm] of PMMA nanofibers at two different spinning distances } \\
\hline & $10 \mathrm{~cm}$ & $15 \mathrm{~cm}$ & $10 \mathrm{~cm}$ & $15 \mathrm{~cm}$ & $10 \mathrm{~cm}$ & $15 \mathrm{~cm}$ \\
\hline 10 & $348 \pm 57$ & $220 \pm 46$ & $589 \pm 89$ & $665 \pm 103$ & $1091 \pm 297$ & $906 \pm 141$ \\
\hline 15 & $286 \pm 36$ & $\mathbf{3 0 7} \pm \mathbf{5 0}$ & $624 \pm 86$ & $708 \pm 87$ & $854 \pm 244$ & $909 \pm 159$ \\
\hline 20 & $348 \pm 62$ & $344 \pm 85$ & $553 \pm 93$ & $586 \pm 65$ & $838 \pm 175$ & $897 \pm 125$ \\
\hline 25 & $323 \pm 42$ & $304 \pm 39$ & $561 \pm 98$ & $415 \pm 44$ & $839 \pm 121$ & $772 \pm 164$ \\
\hline
\end{tabular}

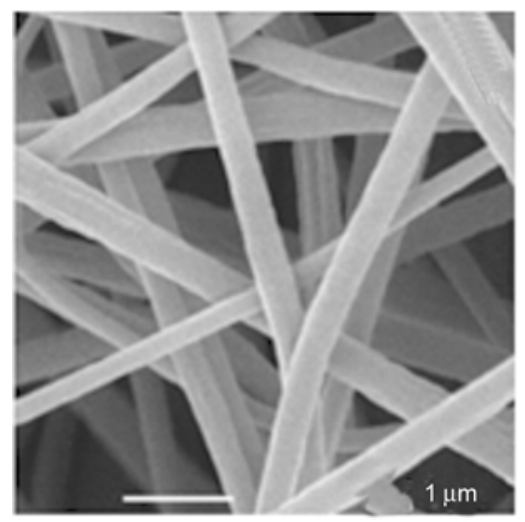

a)

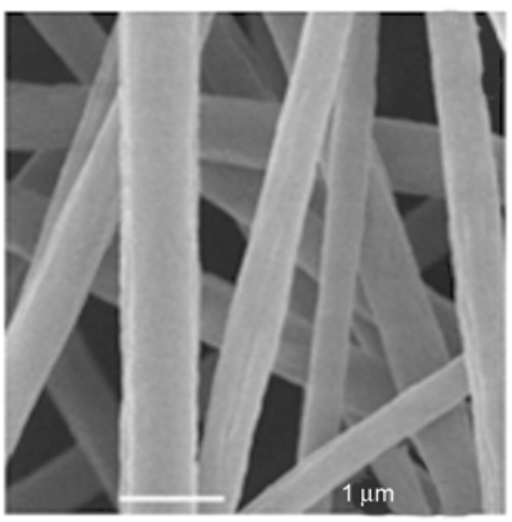

b)

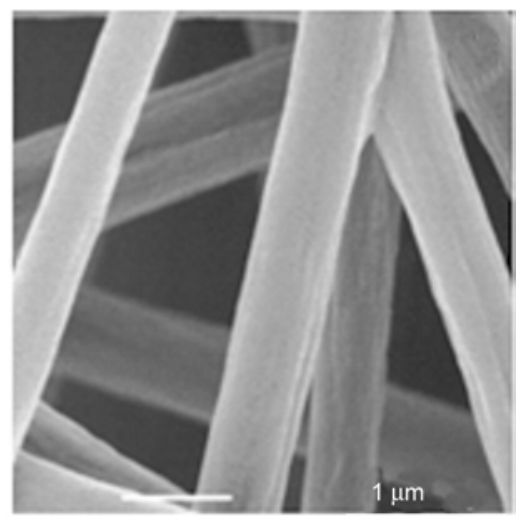

c)

Figure 1. SEM images of (a) 200-400 nm, (b) 400-650 nm and (c) 600-900 nm electrospun PMMA $\mathrm{A}_{\text {high }}$ fibers 
It can be seen that an increase in the applied voltage resulted in a decrease in the fiber diameter for the more concentrated PMMA solution (6 wt $\%$ PMMA) at a shorter spinning distance $(10 \mathrm{~cm})$. No significant changes in the diameters of the less concentrated solutions were observed, however, decreased fiber diameters were observed particularly at higher voltages. The decrease in fiber diameter with an increase in the spinning voltage became more noticeable at increased spinning distance (Table 1). The effect was observed for the more concentrated polymer solutions (5 and $6 \mathrm{wt} \%$ PMMA).

\section{Effect of spinning distance}

It can be seen from Table 1 that an increase in the spinning distance generally seemed to favour the production of nanofibers with slightly reduced diameters in this instance, depending on the spinning voltage. Some researchers mentioned that an increase in spinning distance resulted in a significant reduction in the diameter of the fibers for different polymers, including PMMA of a significantly lower molecular weight [23]. This indicates that different polymers or different molecular weights of the same polymer behave differently towards changing of the electrospinning parameters.

\subsection{Thermal analysis of electrospun PMMA nanofibers}

Differential scanning calorimetry (DSC) was done on the electrospun PMMA nanofibers in order to determine the thermal behaviour of the nanofibers. The results are presented in Figure 2. It can be seen from Figure 2 that the glass transitions $\left(T_{\mathrm{g}}\right)$ of the PMMA nanofibers and the PMMA matrix sheet are

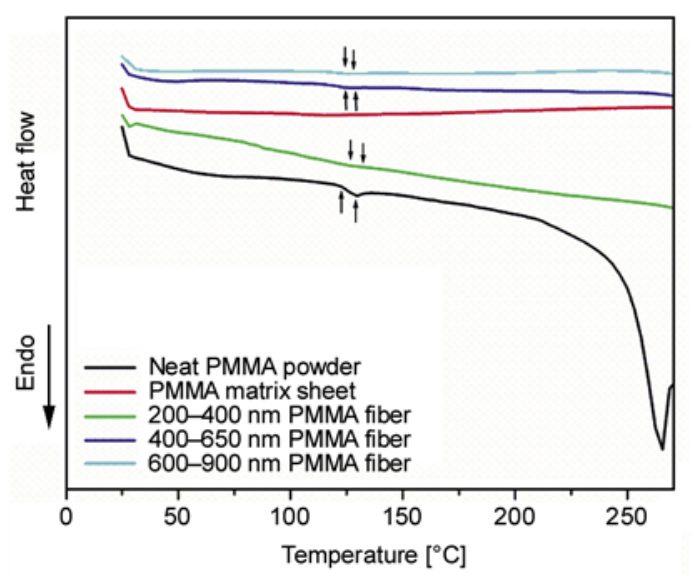

Figure 2. DSC results of $\mathrm{PMMA}_{\text {high }}$ powder, $\mathrm{PMMA}_{\text {high }}$ nanofibers and PMMA matrix sheet not clearly visible as compared to the neat powder. However, the DMA (discussed in section 3.3) shows the clear indication of the $T_{\mathrm{g}}$ of the matrix. Moreover, it is indicated that the nanofibers and the PMMA matrix sheet are thermally more stable than the as-received high molecular weight PMMA powder.

\subsection{PMMA single polymer composites}

Investigation of processing conditions for single polymer composites of PMMA

The effect of the processing temperature on the morphology of the composites was investigated. The aim was to find a suitable processing temperature for the preparation of a quality PMMA single polymer composite. Since PMMA is amorphous, the amount of orientation (although not determined in this study) in the electrospun nanofibers will determine the processing window. SEM analysis of the cross-sections of the PMMA composites was used to check the intactness of the nanofibers and the integrity of the interface between the matrix and the reinforcement. PMMA ${ }_{\text {high }}$ nanofibers with a diameter ranging from $400-650 \mathrm{~nm}$ were used to investigate suitable processing conditions for preparing single polymer composites of PMMA. PMMA was used as the matrix material.

Figure 3 shows the SEM images of the composites prepared at 140,150 and $160^{\circ} \mathrm{C}$. The processing temperatures are well above the glass transition $\left(T_{\mathrm{g}}\right)$ of PMMA. The SEM images of the composites prepared at 140 and $150^{\circ} \mathrm{C}$ show two phases. Thus, the composites have a layered structure consisting of outer film layers and a layer in-between, which is associated with the non-woven nanofiber mats plus the softened matrix which has diffused on nonwoven fiber mat. Possible partial softening of the surface of the non-woven fiber mat is present. This results in a good interface, which should translate into enhanced mechanical properties as a result of efficient stress transfer. The SEM images seem to be in agreement with the previous study of Capiati and Porter [2]. It is likely that the layered structure observed for the composites is due to a combination of two composite fabrication methods, namely film stacking and hot compaction. Hine et al. [24] demonstrated that such a combination of film stacking with hot compaction results in a better overall balance of mechanical properties and a wider tempera- 


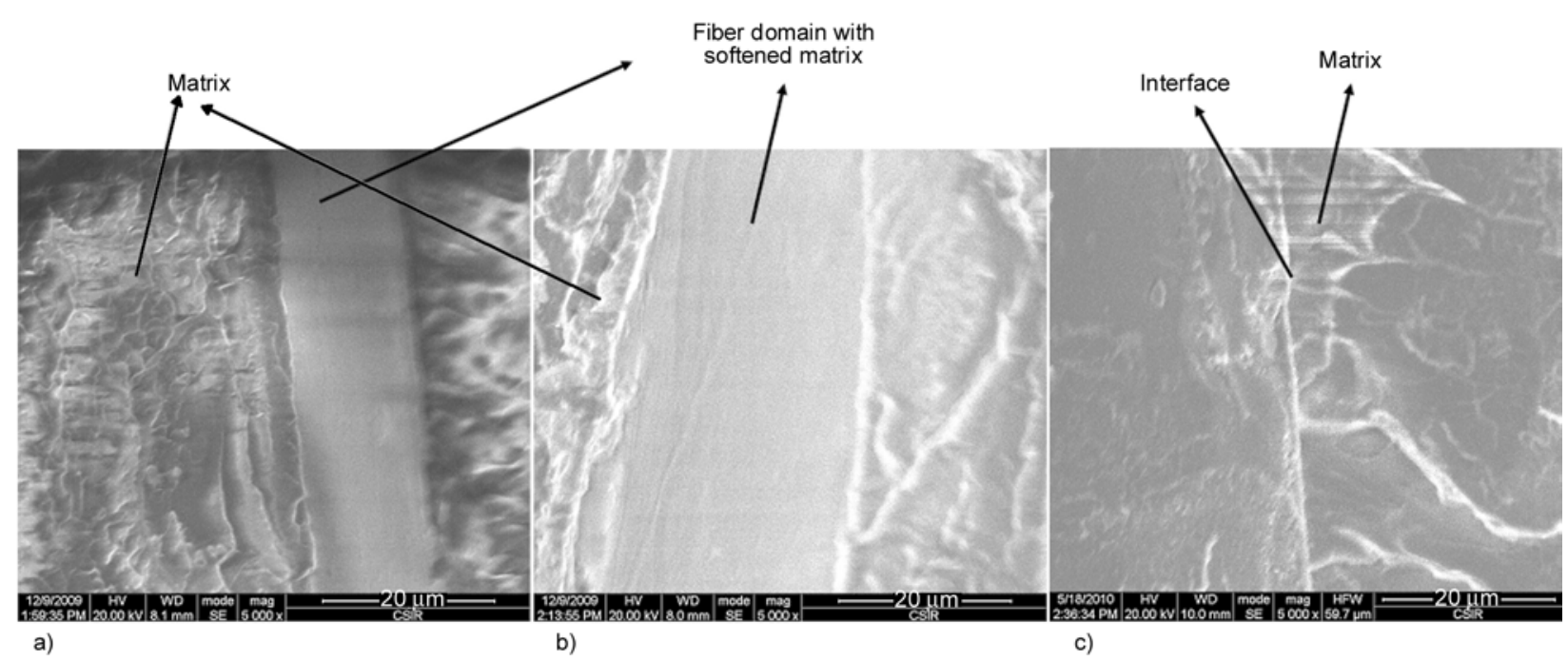

Figure 3. SEM images (scale bar: $20 \mu \mathrm{m}$ ) of PMMA single polymer composites prepared at (a) $140^{\circ} \mathrm{C}$, (b) $150^{\circ} \mathrm{C}$ and (c) $160^{\circ} \mathrm{C}$

ture range for processing compared to a standard compaction procedure without a film. Furthermore, this combination gives rise to better wetting of the reinforcement compared to the traditional film stacking process, due to the partial melting of the entire fiber surface. This better wetting of the fibers results in good interfacial adhesion between the phases, which can be seen from the SEM images in Figure 3.

However, delamination between the different matrix layers for the composites prepared at $140^{\circ} \mathrm{C}$ was observed. This was due to insufficient softening of the matrix material at a processing temperature of $140^{\circ} \mathrm{C}$. The SEM analysis of the composite samples prepared at $160^{\circ} \mathrm{C}$ does not show two well-defined phases (Figure 3c). This suggests that the nanofibers could have also softened in addition to the matrix. Thus, a processing temperature of $160^{\circ} \mathrm{C}$ does not seem to be suitable for the preparation of the PMMA single polymer composites. The best composite with two distinguishable physical phases with adequate melting of the matrix material was therefore obtained at a processing temperature of $150^{\circ} \mathrm{C}$.

Dimension of the layer related to the non-woven fiber mat, as observed from Figure 3, is around 10 to $15 \mu \mathrm{m}$. On the other hand, the diameter of the nonwoven PMMA fibers was found to be around 200$900 \mathrm{~nm}$ (Figure 1 and Table 1). Differences in the nanofiber dimensions, as visualised in Figures 1 and 3, are explained by Figure 4. Before compression moulding, non-woven PMMA fibers mats are entangled among themselves (left hand side of Figure 4). For preparing single polymer composite, PMMA sheets are stacked above and below the non-woven mat. Under pressure, PMMA matrix softens and fills the vacant spaces around non-woven fiber mat.

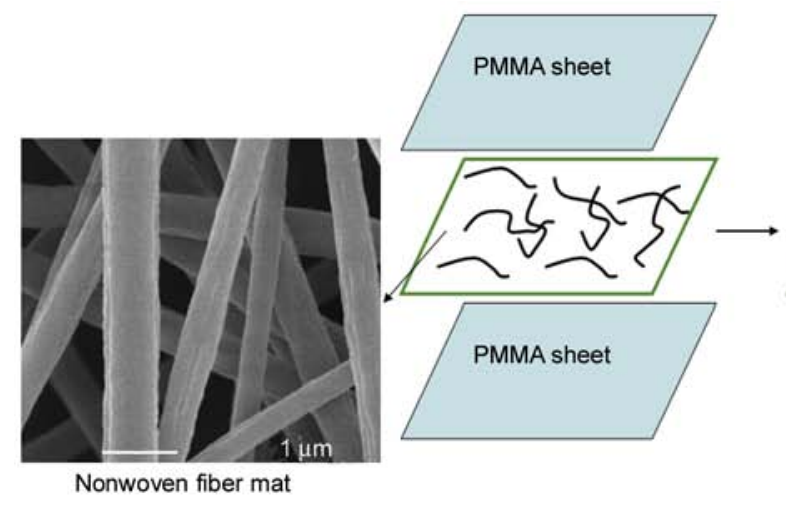

Before compression molding

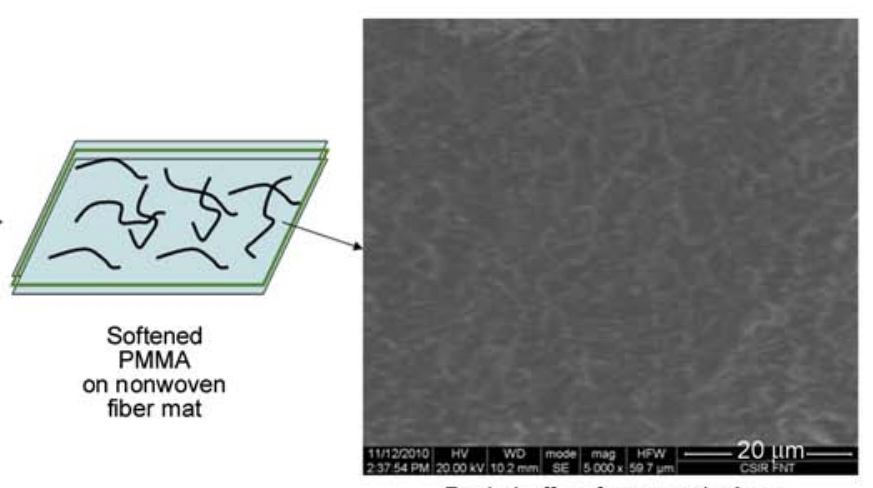

Peeled-off surface morphoéogy

After compression molding

Figure 4. The appearance of PMMA nanofiber non- woven mat in single polymer composites system after compression molding. Scale bar for peeled-off picture is $20 \mu \mathrm{m}$. 
SEM morphology of peeled-off structure after compression moulding (right hand side of Figure 4) demonstrates the presence of softened PMMA as well as non-woven PMMA mat. However, these nanofibers are hidden when the cross-section morphology of the composites are taken. This is attributed to the absence of fiber pull-out from the matrix when fractured.

\section{Preparation and characterisation of single polymer composites of PMMA}

The effects of the nanofiber diameter and nanofiber loading on the dynamic mechanical properties of six different types of PMMA single polymer composites prepared at $150^{\circ} \mathrm{C}$ were investigated. The nanofiber reinforcements consisted of three different fiber diameter ranges at two different loadings. The nanofibers electrospun at $15 \mathrm{kV}$ and $10 \mathrm{~cm}$ at the various concentrations were used to prepare the single polymer composites (Table 1, conditions in bold font). Designations for six different types of composites are presented in Table 2.

The change in storage modulus and damping behaviour $(\tan \delta)$ of the neat PMMA matrix compared to the composites SPC01 to SPC03 with $5 \mathrm{wt} \%$ nanofiber loading are shown in Figure 5. A slightly higher

Table 2. Designations of PMMA single polymer composites

\begin{tabular}{|c|c|c|c|}
\hline \multirow{2}{*}{$\begin{array}{c}\text { Sample } \\
\text { designation }\end{array}$} & \multirow{3}{*}{ Matrix } & \multicolumn{2}{|c|}{ Reinforcement by } \\
\cline { 4 - 4 } & & $\begin{array}{c}\text { 5 wt\% of PMMA } \\
\text { nanofibers [nm] }\end{array}$ & $\begin{array}{c}\text { 10 wt\% of PMMA } \\
\text { nanofibers [nm] }\end{array}$ \\
\hline SPC01 & \multirow{4}{*}{\begin{tabular}{c} 
PMMA \\
\cline { 3 - 3 } sheet
\end{tabular}} & $200-400$ & NA \\
\cline { 4 - 4 } SPC02 & $400-650$ & NA \\
\hline SPC03 & $600-900$ & NA \\
\hline SPC04 & NA & $200-400$ \\
\hline SPC05 & NA & $400-650$ \\
\hline SPC06 & & NA & $600-900$ \\
\hline
\end{tabular}

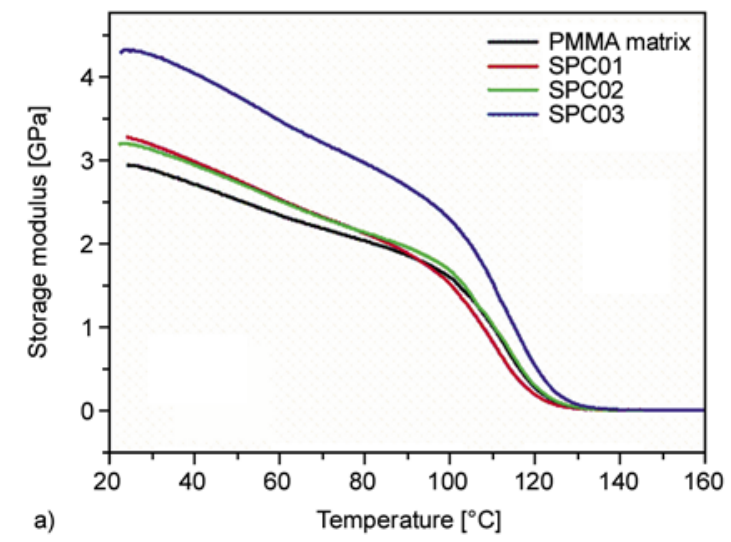

stiffness was observed for SPC01 and SPC02 compared to the neat PMMA matrix. A significantly higher reinforcing affect of the higher diameter fibers at a loading of $5 \mathrm{wt} \%$ was observed. Composite SPC03 showed an increase in stiffness of approximately $46 \%$ compared to the neat PMMA matrix. A slight increase in the peak temperatures of the $\tan \delta$ peaks of the composites compared to the neat PMMA matrix was observed (Figure 5b). This increase is once again more noticeable in SPC03. This means that the inclusion of the nanofibers affected the mobility of the polymer chains to some degree. Furthermore, at a $5 \mathrm{wt} \%$ inclusion of the nanofibers, no significant shift in the peak temperature is observed for SPC01 and SPC02 compared to the neat PMMA matrix. However, the peak temperature shifted marginally by about $4^{\circ} \mathrm{C}$ in the case of SPC03 compared to the matrix. This means that there is stronger physical interaction between the higher diameter nanofibers and the neat PMMA matrix.

The storage modulus and damping behaviour $(\tan \delta)$ of the neat PMMA matrix compared to the composites SPC04 to SPC06 with $10 \mathrm{wt} \%$ nanofiber loading are shown in Figure 6. The stiffness of all the composites was higher than that of the neat PMMA matrix. A maximum improvement in stiffness of $83 \%$ compared to the matrix was obtained. This is due to the reinforcing effect of the nanofibers. Different stiffness and damping behaviour was observed for the composites with $10 \mathrm{wt} \%$ nanofiber loading compared to the ones with a $5 \mathrm{wt} \%$ nanofiber loading. The composites (SPC04 and SPC05) reinforced with fibers of smaller diameters showed a larger improvement in stiffness compared to the one reinforced with the highest diameter fibers. This is con-

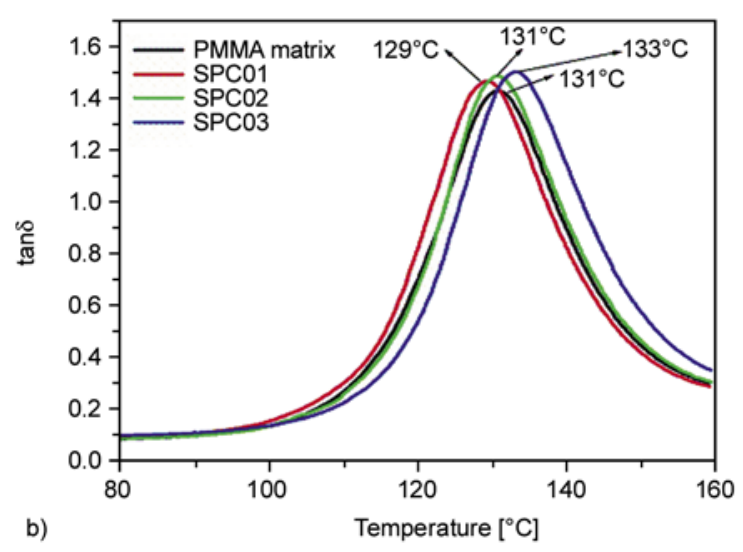

Figure 5. Effect of fiber diameter on the storage modulus (a) and $\tan \delta$ (b) for PMMA composites at 5 wt $\%$ nanofiber loading and processing temperature of $150^{\circ} \mathrm{C}$ 

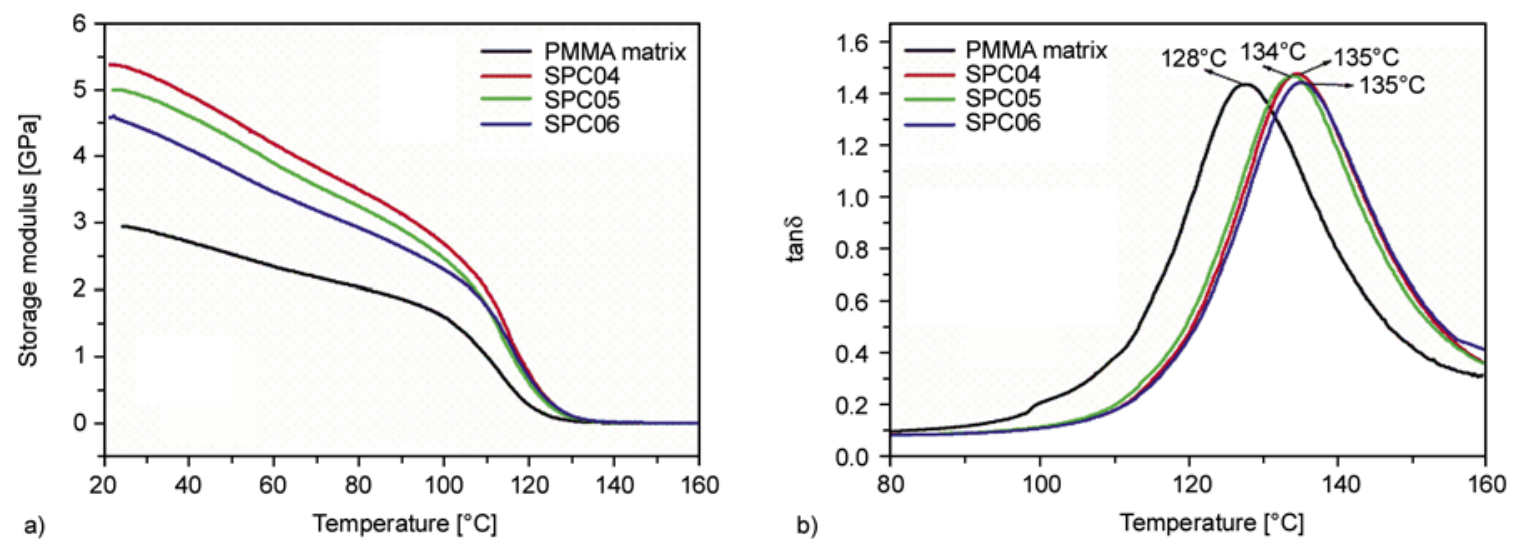

Figure 6. Effect of fiber diameter on the storage modulus (a) and $\tan \delta$ (b) for PMMA composites at $10 \mathrm{wt} \%$ nanofiber loading and processing temperature of $150^{\circ} \mathrm{C}$

trary to what was observed for the composites with a $5 \mathrm{wt} \%$ nanofiber loading. This is probably as a result of the higher fiber content and the larger surface area of the nanofibers with smaller diameters. In this case an increase in the stiffness of the composites is observed as the diameter of the reinforcement decreases. In addition, a less pronounced decrease in the stiffness of all the composites compared to the neat PMMA matrix was observed. Figure $6 \mathrm{~b}$ shows the damping behaviour of the neat PMMA matrix compared to the composites reinforced with a $10 \mathrm{wt} \%$ nanofiber loading. Similar damping behaviour is observed for all the composites. The addition of a $10 \mathrm{wt} \%$ nanofiber loading had no significant effect on the maximum value of the $\tan \delta$ peaks of the composites. Thus, the mobility of the polymer chains in the matrix and the composites are quite similar. Nevertheless, the position of the $T_{\mathrm{g}}$ of the composites shifted to higher temperatures as compared to the PMMA matrix. This shift to higher temperatures is attributed to the increase in the stiffness of the composites due to reinforcement effect of the nanofibers.

\section{Conclusions}

In this study, the effects of processing parameters on the morphology of electrospun PMMA fibers have been investigated. PMMA nanofibers with diameters ranging from $200-900 \mathrm{~nm}$ were prepared under various conditions. The SEM analysis of the PMMA nanofibers showed that the fibers had a smooth, regular and cylindrical morphology with no beads and junctions. The spinning voltage and the spinning distance, in general, did not have a sig- nificant influence on the morphology and diameters of the fibers. However, an increase in polymer solution concentration resulted in a significant increase in fiber diameter. The processing conditions for the preparation of single polymer composites of PMMA were investigated. It was determined that a processing temperature of $150^{\circ} \mathrm{C}$ was adequate for the preparation of a good composite because at this temperature distinct layer of fibers and matrix were observed. The composites generally showed an improvement in dynamic mechanical properties compared to the neat PMMA matrix. The increases in the stiffness (up to $83 \%$ ) and glass transition temperatures (up to $10^{\circ} \mathrm{C}$ ) of the composites were pronounced in the case of a $10 \mathrm{wt} \%$ nanofiber loading.

\section{Acknowledgements}

The author would like to thank Mrs. Valencia Jacobs for SEM analysis and Council for Scientific and Industrial Research of South Africa for financial assistance.

\section{References}

[1] Kmetty A., Bárány T., Karger-Kocsis J.: Self-reinforced polymeric materials: A review. Progress in Polymer Science, 35, 1288-1310 (2010).

DOI: $10.1016 /$ j.progpolymsci.2010.07.002

[2] Capiati N. J., Porter P. S.: The concept of one polymer composites modelled with high density polyethylene. Journal of Materials Science, 10, 1671-1677 (1975). DOI: $10.1007 / \mathrm{BF} 00554928$

[3] Mosleh M., Suh N. P., Arinez J.: Manufacture and properties of a polyethylene homocomposite. Composites Part A: Applied Science and Manufacturing, 29, 611-617 (1998).

DOI: $10.1016 / \mathrm{S} 1359-835 \mathrm{X}(97) 00122-\mathrm{X}$ 
[4] Loos J., Schinanski T., Hofman J., Peijs T., Lemstra P. $\mathrm{J} .:$ Morphological investigations of polypropylene single-fibre reinforced polypropylene model composites. Polymer, 42, 3827-3834 (2001).

DOI: 10.1016/S0032-3861(00)00660-1

[5] Hine P. J., Astruc A., Ward I. M.: Hot compaction of polyethylene naphthalate. Journal of Applied Polymer Science, 93, 796-802 (2004).

DOI: $10.1002 / a p p .20517$

[6] Li R., Yao D.: Preparation of single poly(lactic acid) composites. Journal of Applied Polymer Science, 107, 2909-2916 (2008).

DOI: $10.1002 / a p p .27406$

[7] Gong Y., Yang G.: All-polyamide composites prepared by resin transfer molding. Journal of Materials Science, 45, 5237-5243 (2010).

DOI: $10.1007 / \mathrm{s} 10853-010-4565-6$

[8] Wright D. D., Lautenschlager E. P., Gilbert J. L.: Bending and fracture toughness of woven self-reinforced composite poly(methyl methacrylate). Journal of Biomedical Materials Research, 36, 441-453 (1997). DOI: 10.1002/(SICI)1097-4636(19970915)36:4<441::

$$
\text { AID-JBM2>3.0.CO;2-E }
$$

[9] Wright-Charlesworth D. D., Lautenschlager E. P., Gilbert J. L.: Hot compaction of poly(methyl methacrylate) composites based on fiber shrinkage results. Journal of Materials Science: Materials in Medicine, 16, 967-975 (2005).

DOI: $10.1007 / \mathrm{s} 10856-005-4431-2$

[10] Bárány T., Karger-Kocsis J.: Development and characterization of self-reinforced poly(propylene) composites: Carded mat reinforcement. Polymers for Advanced Technologies, 17, 818-824 (2006).

DOI: $10.1002 /$ pat. 813

[11] Hine P. J., Ward I. M., Jordan N. D., Olley R., Bassett D. C.: A comparison of the hot-compaction behavior of oriented, high-modulus, polyethylene fibers and tapes. Journal of Macromolecular Science: Physics, 40, 959-989 (2001).

DOI: $10.1081 / \mathrm{MB}-100107570$

[12] Alcock B., Cabrera N. O., Barkoula N-M., Reynolds C. T.: The effect of temperature and strain rate on the mechanical properties of highly oriented polypropylene tapes and all-polypropylene composites. Composites Science and Technolology, 67, 2061-2070 (2007). DOI: 10.1016/j.compscitech.2006.11.012

[13] Bárány T., Izer A., Karger-Kocsis J.: Impact resistance of all-polypropylene composites composed of alpha and beta modifications. Polymer Testing, 28, 176-182 (2009).

DOI: $10.1016 /$ j.polymertesting.2008.11.011
[14] Yao D., Li R., Nagarajan P.: Single-polymer composites based on slowly crystallizing polymers. Polymer Engineering and Science, 46, 1223-1230 (2006). DOI: $10.1002 /$ pen.20583

[15] Dzenis Y.: Spinning continuous fibers for nanotechnology. Science, 304, 1917-1919 (2004). DOI: $10.1126 /$ science. 1099074

[16] Li D., Xia Y.: Electrospinning of nanofibers: Reinventing the wheel? Advanced Materials, 16, 1151-1170 (2004).

DOI: $10.1002 / \mathrm{adma} .200400719$

[17] Teo W. E., Ramakrishna S.: A review on electrospinning design and nanofibre assemblies. Nanotechnolgy, 17, 89-106 (2006). DOI: $10.1088 / 0957-4484 / 17 / 14 / \mathrm{R} 01$

[18] Formhals A.: Process and apparatus for preparing artificial threads. U.S. Patent 1975504, USA (1934).

[19] Liu J., Kumar S.: Microscopic polymer cups by electrospinning. Polymer, 46, 3211-3214 (2005). DOI: $10.1016 /$ j.polymer.2004.11.116

[20] Wang H., Li Q., Yang Q., Li Y., Wang W., Sun L., Zhang C., Li Y.: Electrospun poly(methyl methacrylate) nanofibers and microparticles. Journal of Materials Science, 45, 1032-1038 (2010). DOI: $10.1007 / \mathrm{s} 10853-009-4035-1$

[21] Sill T. J., von Recum H. A.: Electrospinning: Applications in drug delivery and tissue engineering. Biomaterials, 29, 1989-2006 (2008).

DOI: $10.1016 /$ j.biomaterials.2008.01.011

[22] Jacobs V., Anandjiwala R. D., Maaza M.: The influence of electrospinning parameters on the structural morphology and diameter of electrospun nanofibers. Journal of Applied Polymer Science, 115, 3130-3136 (2010). DOI: $10.1002 / a p p .31396$

[23] Doshi J., Reneker D. H.: Electrospinning process and applications of electrospun fibers. Journal of Electrostatics, 35, 151-160 (1995).

DOI: 10.1016/0304-3886(95)00041-8

[24] Hine P. J., Olley R. H., Ward I. M.: The use of interleaved films for optimising the production and properties of hot compacted, self reinforced polymer composites. Composites Science and Technology, 68, 1413-1421 (2008).

DOI: 10.1016/j.compscitech.2007.11.003 